\title{
Goals, Motivation and Gender
}

\author{
Samuel Smithers* \\ Department of Economics, University of Leicester, Leicester, LE1 7RH
}

\begin{abstract}
I present an experiment on non-binding goals and motivational effects. Consistent with results from psychology, I find that goals increase output. This is due to improved speed and accuracy. Men are more responsive to goals than women.
\end{abstract}

Keywords: Goal Setting, Motivation, Gender Differences JEL J16, C91, M50

\section{Introduction}

A non-binding goal is a specific, challenging target with which there are no monetary rewards or punishments associated with success or failure. Such a goal should have no impact in an environment in which only final wealth levels matter, and only monetary rewards or punishments affect behaviour. However, I examine the effect of non-binding goals on effort using a timed addition task, similar to Niederle and Vesterlund (2007). I have three treatments: no goal, low goal and high goal in which I use the number of correct additions as a measure of effort. I find that goals promote speed and accuracy. Men are more responsive to goals than women.

The traditional view in labour economics is that monetary incentives consistently and predictably improve effort (Rebitzer and Taylor, 2011). Challenging this view, Ariely et al. (2009) find that paying people a lot leads to worse performance on mental tasks in the US and India. Gneezy and Rustichini (2000) find that low monetary incentives lead to worse performance than not paying at all.

I find that goal-setting, a motivational tool used by psychologists and managers, mostly overlooked by economists, can generate the desired positive effect of monetary incentives without the monetary cost. The motivation for this paper is Latham and Locke (1991)'s finding that setting a goal has some key properties: an increase in effort (energy put into the task), persistence (time spent on the task), attention (more focus on the task with the set goal and away from non-relevant activities) and it encourages the use and acquisition of knowledge.

The economics literature on these effects is sparse. There is work on how goals can help conquer self-control problems (Hsiaw, 2013; Koch and Nafziger, 2011) and on how individual personal standards affect the goal-effort relationship (Gómez-Miñambres, 2012), but the effect of goals has gone untested in economics. ${ }^{1}$ I test if goals increase effort, which would support the theory that intrinsic motivation is higher with goals. Heath et al. (1999) propose that goals can act as a reference point for evaluating performance. This psychological utility explains how a non-binding goal may have effects. Supporting this, Camerer et al. (1997) find that taxi drivers have a one-day time horizon and set themselves daily income targets (i.e. goals).

This paper contributes to the literature in two ways. First, I find that the mean effort under the high and low goals are $35 \%$ and $20 \%$ higher than in the control group. I also observe an increase in speed and accuracy by those with a goal. Second, contrary to the psychology literature, I find a gender difference such

\footnotetext{
*Tel:+44 1162522233

Email address: sfts1@le.ac.uk (Samuel Smithers)

${ }^{1}$ Since writing, Gómez-Miñambres et al. (2015) have forthcoming results looking at the interaction between goal levels and monetary incentives.
} 
that women perform better than men in the no goal setting but men thrive in both of the goal treatments. The results suggest that men are more responsive to goal than women.

\section{Experimental Design}

Participants solve a real effort task under a standard piece rate setting. Following the task of Niederle and Vesterlund (2007), the participants face a simple addition task summing up sets of five two-digit, randomly drawn numbers over five minutes, where participants provide the solution by writing the sum in the empty box:

\begin{tabular}{|l|l|l|l|l|l|}
\hline 51 & 37 & 85 & 15 & 21 & -- \\
\hline
\end{tabular}

The task is selected as it is sufficiently cognitively demanding to require effort and focus to complete, but also it is a task which all participants have the skills to undertake. ${ }^{2}$

The number of correctly solved problems is interpreted as the effort exerted. Subjects receive 25p per correct answer on the addition task.

In each session participants were randomly assigned to either the control, low goal or high goal. The random assignment is given by a clear, extra line of instruction stating "For this task you have a goal to get 10 (15) correct additions". ${ }^{3}$

Participants also completed a small GMAT style test of five questions in five minutes just prior to the addition task. This task can be used to identify the underlying ability of the participants (Oswald et al., 2014). Participants were rewarded 50p per correct answer and were informed of their results at the end of the experiment. The experiment concluded with a questionnaire asking for typical demographics including age, gender and education.

The subjects were informed that all information gathered will be kept anonymous and that it is key that they read everything that is presented to them carefully. The experiment had no show up fee as, owing to the experiments short duration, the show up fee would overpower the piece rate.

\section{Results}

The experiment was conducted at the University of Leicester UK, using subjects recruited from the student body. In total 109 participants took part, 36 in each of the control and goal-10 treatments and 37 in the goal-15 treatment. The experiment took 15 minutes and participants earned on average £4.50. Figure 1 summarises the main results.

The control, goal-10 and goal-15 treatments had mean scores (s.d.) of 8.72 (4.80), 10.53 (3.71) and 11.78 (5.24) respectively. On average, scores in the goal-10 treatment were 1.81 additions higher than the control group $(p=0.079) .{ }^{4}$ Furthermore, scores in the goal-15 treatment were 3.06 additions higher than the control group $(p=0.011)$. However, the goal treatments were not significantly different $(p=0.242)$, suggesting that having a goal is more important than the specific value of the goal.

Looking at the average number of questions attempted, the control group attempted 11.28 questions with the goal-10 group attempting 1.1 extra $(p=0.285)$, and the goal-15 group attempting 1.94 more $(p=0.087)$. These are $10 \%$ and $17 \%$ increases in speed over the control group.

The accuracy, calculated as the number of correct additions over the number of problems attempted, is illustrated in Figure 2. The mean accuracy is $74 \%$ for the control group, $85 \%$ for the goal- 10 treatment and $87 \%$ for the goal-15 treatment. Both the goal-10 and the goal-15 treatments were significantly more accurate

\footnotetext{
${ }^{2}$ It was found to be a gender neutral task (Niederle and Vesterlund, 2007).

315 was only achieved by the top $20 \%$ in the pilot and 10 was the mean.

${ }^{4}$ In an effort to remain conservative all $t$-test $p$-values are for two-sided tests, even though the hypothesis, which suggests the sign of the effects, provides some justification for conducting one sided-tests. Wilcoxon rank-sum tests give very similar results to all presented t-test p-values. Further robustness checks are performed controlling for maths skills (GMAT). The results of these checks are still robust.
} 


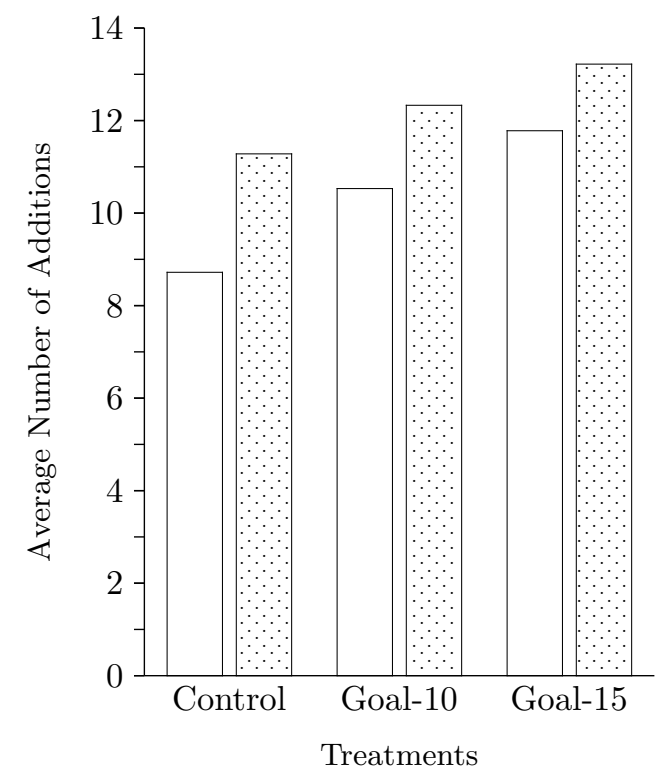

Figure 1: Addition task results by treatment (Correct $\square$, Attempted $\square$ )

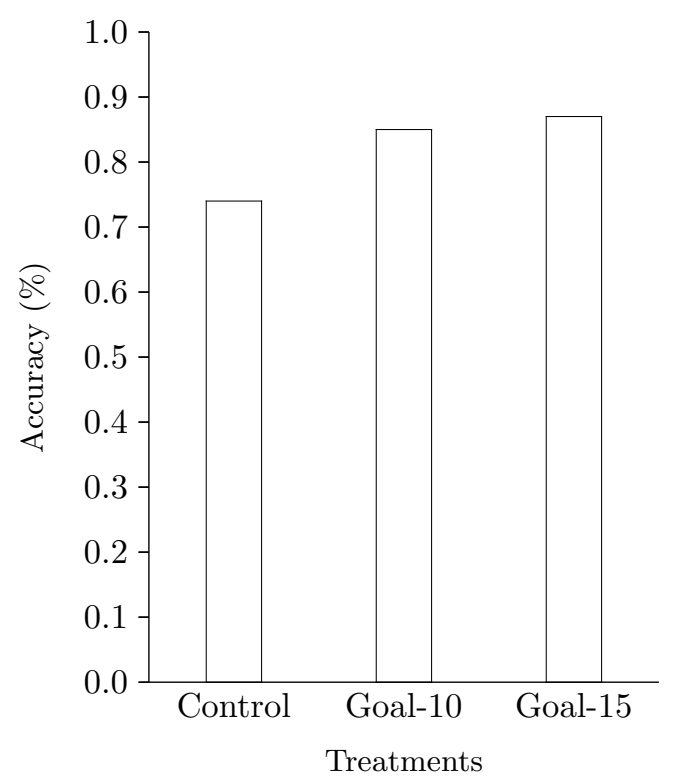

Figure 2: Average accuracy in addition task by treatment

than the control group $(p=0.015$ and $p=0.002)$. However there is no significant difference between the two goal treatments $(p=0.458)$, implying that those with a goal gave greater attention to the addition task than the control group.

Looking at the increase in scores, questions attempted and accuracy, the results imply that those in the goal treatments were exerting more effort, calculating answers quicker and more accurately. This suggests that effort, which is the product of speed and accuracy, can be jointly enhanced at no extra monetary cost.

Table 1 shows the monetary value of each goal, which can be calculated as the difference between the average score under the goal treatments and the control group multiplied by the value of output (25p). Over a five minute interval this is a significant increase. Over an hour, assuming that effort level could be sustained, the value of setting a high goal over no goal would be worth £9.24 per person. 


\begin{tabular}{ccc}
\hline Group & Extra Additions & $(£)$ Value \\
\hline Goal-10 & 1.81 & 0.45 \\
Goal-15 & 3.06 & 0.77 \\
\hline
\end{tabular}

Table 1: Monetary Value of Goal Setting

Latham and Locke (1991) mention that there is "little evidence that $[\ldots]$ gender [...] moderate[s] the goal-performance relationship". Yet men appear to embrace the challenge of a goal more than women. One reason could be that the goal creates a competitive environment, which is consistent with the literature on how competition affects men and women differently (Gneezy and Rustichini, 2004; Niederle and Vesterlund, 2007).

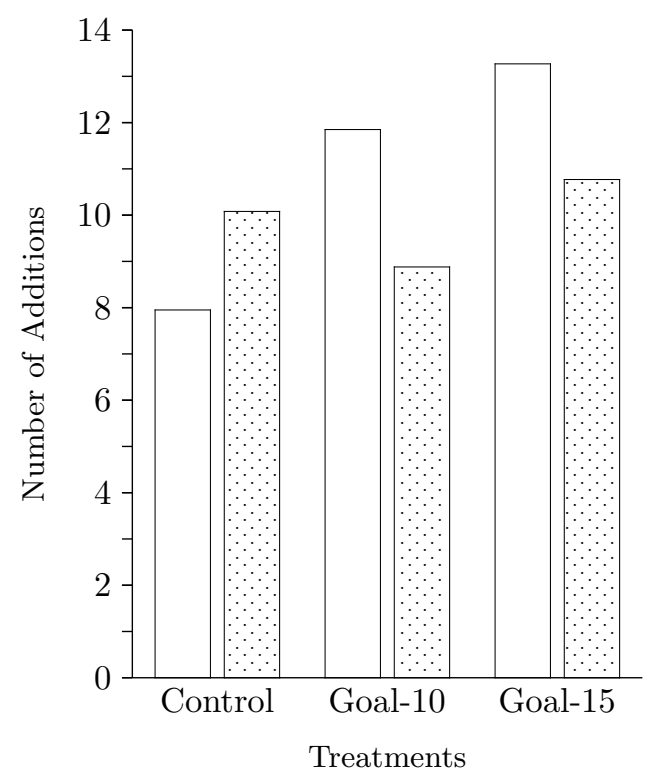

Figure 3: Effort across treatments by gender (Male $\square$, Female $\square$ )

There was no significant difference in the overall mean score for men $(10.67 ;$ s.d. $=5.19$ and women $(10.00$; s.d.=4.24) $(p=0.464)$. However, comparing the differences across treatments, as shown in Figure 3 , the addition score of women on average remains relatively unaffected when introducing a goal, whereas men thrived under the goal. ${ }^{5}$ Men in the goal-10 treatment scored on average 3.89 additions more than men in the control group $(p=0.004)$ and for the goal-15 treatment, on average 5.31 additions more $(p=0.006)$. The men's score was significantly different from the women's for the goal-10 treatment $(p=0.014)$ but the goal-15 ( $p=0.158)$ treatment just falls short of statistical significance using a two-sided test.

\section{Conclusion}

This paper addresses the topic of exogenously given non-binding goals in a real performance task. I find that setting a goal induces higher effort. I show that this effect is driven by an increase in both speed and accuracy. Further research is needed to test the link between the level of incentives and the responsiveness to goals. Furthermore, a greater variance in the goal level needs to be examined to get a full picture of how people respond to goals.

\footnotetext{
${ }^{5}$ For women's performance, goal-10 $(p=0.444)$, goal-15 $(p=0.654)$ are not significantly different from the control group.
} 
This paper echoes results found by Locke and Latham (1990) on the effects of goals on effort in psychology. This paper is the first, though, to identify a gender difference: male participants thrived when presented with a non-binding goal, whereas female participants were unaffected. This result resonates with findings on gender differences in preferences (Croson and Gneezy, 2009) - in particular in the context of competition (Gneezy and Rustichini, 2004; Migheli, 2015; Niederle and Vesterlund, 2007). Future research should try to disentangle how much utility is derived from both the psychological effect of reaching a goal and the competition component (Guryan et al., 2009).

\section{Acknowledgements}

I would like to thank the ESRC for funding my PhD studies, staff at the Department of Economics, University of Leicester for helpful discussions and an anonymous referee. Thanks also to my supervisors Sanjit Dhami, Ali Al-Nowaihi, and with special thanks to my external supervisor Alexander Smith.

\section{References}

Ariely, D., Gneezy, U., Loewenstein, G., Mazar, N., 2009. Large stakes and big mistakes. Rev. Econ. Stud. 76 (2), $451-469$. Camerer, C., Babcock, L., Loewenstein, G., Thaler, R., 1997. Labor supply of new york city cabdrivers: One day at a time. Q. J. Econ. 112 (2), 407-441.

Croson, R., Gneezy, U., 2009. Gender differences in preferences. J. Econ. Lit. 47 (2), $448-74$.

Gneezy, U., Rustichini, A., 2000. Pay enough or don't pay at all. Q. J. Econ. 115 (3), 791-810.

Gneezy, U., Rustichini, A., 2004. Gender and competition at a young age. Amer. Econ. Rev. 94 (2), $377-381$.

Gómez-Miñambres, J., 2012. Motivation through goal setting. J. Econ. Psychol. 33 (6), 1223-1239.

Gómez-Miñambres, J., Corgnet, B., Gonzalez, R., 2015. Goal setting and monetary incentives: When large stakes are not enough. Manag. Sci.In Press.

Guryan, J., Kroft, K., Notowidigdo, M., 2009. Peer effects in the workplace: Evidence from random groupings in professional golf tournaments. Amer. Econ. J.: Appl. Econ. 1 (4), 34-68.

Heath, C., Larrick, R., Wu, G., 1999. Goals as reference points. Cogn. Psychol. 38 (1), 79-109.

Hsiaw, A., 2013. Goal-setting and self-control. J. Econ. Theory 148 (2), 601-626.

Koch, A., Nafziger, J., 2011. Self-regulation through goal setting. Scand. J. Econ. 113 (1), $212-227$.

Latham, G., Locke, E., 1991. Self-regulation through goal setting. Organ. Behav. Hum. Decis. Process. 50 (2), $212-247$.

Locke, E., Latham, G., 1990. A theory of goal setting \& task performance. Prentice Hall.

Migheli, M., 2015. Gender at work: Incentives and self-sorting. J. Behav. Exp. Econ.In Press.

Niederle, M., Vesterlund, L., 2007. Do women shy away from competition? Do men compete too much? Q. J. Econ. 122 (3), 1067-1101.

Oswald, A., Proto, E., Sgroi, D., 2014. Happiness and productivity. J. Labor Econ.In Press.

Rebitzer, J., Taylor, L., 2011. Extrinsic rewards and intrinsic motives: Standard and behavioural approaches to agency and labor markets. In: Ashenfelter, O., Card, D. (Eds.), Handb. Labor Econ., Vol. 4A, 1st Edition. North Holland, pp. $702-722$. 